\title{
Modeling the adoption of energy efficient retrofits by mid-tier commercial buildings
}

\author{
$\underline{\text { Leorey Marquez }}^{\mathrm{a}}$, James McGregor $^{\mathrm{b}}$, Seongwon Seo ${ }^{\mathrm{c}}$, Andrea Walton $^{\mathrm{c}}$, Magnus Moglia ${ }^{\mathrm{c}}$, \\ Andrew Higgins ${ }^{c}$ and John Gardner ${ }^{c}$ \\ ${ }^{a}$ CSIRO Digital Productivitiy, Gate 5, Normanby Road, Clayton VIC, Australia 3168 \\ ${ }^{b}$ CSIRO Energy Transformed, Newcastle NSW, Australia 2304 \\ ${ }^{c}$ CSIRO Land and Water,41 Boggo Road, Dutton Park, QLD, Australia 4102 \\ Email: leorey.marquez@csiro.au
}

\begin{abstract}
The low uptake of cost effective, energy efficient retrofits for commercial buildings suggests that economic considerations are not the sole determinant for their adoption. Socio-psychological surveys provide additional insights into consumption behaviour reflecting important lifestyle, attitudinal, risk, familiarity of technology, cultural and other forms of demographic preferences. There is a need for an evidence based tool that can forecast the effectiveness of intervention options for commercial buildings whilst removing the confounding effects of business-as-usual strategies. This paper describes a framework for evaluating the uptake of building retrofits under various government policy and behaviour program interventions aimed at reducing carbon emissions. The framework incorporates socio-psychological factors into an agent based model, applying diffusion and discrete choice modeling in evaluating the effectiveness of intervention programs, especially those involving direct subsidies (e.g. rebate to upfront costs, tax deductions) to facilitate the uptake of low carbon living practices. This framework is implemented in the ZEO Uptake Analysis Tool which allows planners, researchers and policy makers to assess the relative impact of assumptions about future technology and policy using a defined baseline (or "business as usual" scenario) for comparison. The Tool uses agent-based modeling and simulation (ABMS) to encapsulate the attributes and behaviour of various elements and entities in the building retrofit problem. The paper presents preliminary results from application of the agent-based model to the State of Victoria building stock, in a case study to understand the potential of the Energy Efficient Office Buildings Program in the uptake of energy efficient retrofits. The analysis indicates that the proposed policy options offered by EEOB have very little impact when we consider small building owners and limit the application to building tuning only. There is improvement in uptake when we expand the eligibility to all technologies (excluding lighting) and this is dominated by HVAC (Chiller) upgrades.
\end{abstract}

Keywords: $\quad$ Agent-based modeling, simulation modeling, energy efficient retrofits, commercial buildings 


\section{INTRODUCTION}

The low uptake of cost effective, energy efficient retrofits for commercial buildings suggests that economic considerations are not the sole determinant for their adoption. Socio-psychological surveys provide insights into consumption behaviour reflecting important lifestyle, attitudinal, risk, familiarity of technology, cultural and other forms of demographic preferences. Marquez et al (2012) presents a comprehensive review of the barriers (economic and non-economic) preventing the adoption of energy efficiency measures for existing buildings and discusses their relationship to the different stakeholders associated with the construction, usage, operation and management of commercial buildings. There is a need for an evidence based method that can help explain the dynamics and interactions between intervention schemes and technology adoption in order to help develop policy that will optimise the timing and size of the intervention options.

This paper describes a framework for evaluating the uptake of building retrofits under various government policy and behaviour program interventions aimed at reducing carbon emissions. The framework incorporates socio-psychological factors into an agent based model and simulation (ABMS), applying diffusion and discrete choice modeling in evaluating the effectiveness of intervention programs, especially those involving direct subsidies (e.g. rebate to upfront costs, tax deductions) to facilitate the uptake of low carbon living practices. The paper presents preliminary results from the application of the model to the State of Victoria building stock, in a case study to understand and maximise the potential of government interventions such as the Energy Efficient Office Buildings (EEOB) program.

\subsection{The EEOB Program}

The State of Victoria, through Sustainability Victoria, provides funding and support to improve the energy efficiency of mid-tier commercial office buildings through the Energy Efficient Office Buildings (EEOB) program. Eligible building owners can avail of matching funding grants of $\$ 20,000$ to $\$ 150,000$ to carry out a comprehensive energy efficiency analysis, building tuning, and metering and monitoring activities to improve building performance. This can include reviewing the operation of lighting, lifts, and heating, ventilation and air-conditioning (HVAC) systems, passive systems and implementing cost-effective operational and maintenance improvements to deliver energy savings. The program is specifically targeted at mid-tier commercial office buildings - i.e. those buildings that are not considered premium or A-grade buildings by the Property Council of Australia (Sustainability Victoria, 2013).

The EEOB program provides funding and support for eligible building owners to carry out the following activities (Sustainability Victoria, 2013):

1. Opportunities Analysis - provides an efficiency audit and report on the current energy efficiency of building systems such as lighting, lifts, and heating, ventilation and air-conditioning (HVAC) systems, passive systems and identifies opportunities for improvement.

2. Building tuning - delivers simple, cost-effective energy efficient building upgrades through the tuning of building services and operations. This will identify and correct building system problems to maintain optimal building performance.

3. Monitoring - implements metering and monitoring to enable an evaluation of building performance for the 12 month period following building tuning, in order to measure the effectiveness and cost savings achieved through the building tuning upgrades.

While the EEOB program is focused on identifying and implementing low-cost tuning activities to achieve the greatest cost savings, the program can also provide recommendations on more substantial capital upgrades and savings that building owners can achieve in future years (Sustainability Victoria, 2013).

\subsection{ZEO Uptake Analysis Tool}

Efficiency programs that target building retrofits should be tailored to specific building demographics and regions in order to achieve the maximum return on invested resources (administration) and allocated funds (Davis Langdon, 2013). The environmental impact and effectiveness of voluntary schemes relying on industry and/or consumer adoption, such as the EEOB, are very difficult to evaluate and project into future scenarios (Higgins et al., 2012). There is a need for an assessment tool that can help uncover the dynamics 
and interactions between intervention schemes and technology adoption in order to help develop policy that will optimise the timing and size of the intervention options.

The Low Carbon Living Collaborative Research Centre (LCL-CRC) has developed a framework for evaluating the uptake of building retrofits under various government policy and behaviour program interventions aimed at reducing carbon emissions (Higgins et al., 2012). This framework is implemented in the ZEO Uptake Analysis Tool which allows planners, researchers and policy makers to assess the relative impact of assumptions about future technology and policy using a defined baseline (or "business as usual" scenario) for comparison. The Tool uses agent-based modeling and simulation (ABMS) to encapsulate the attributes and behaviour of various elements and entities in the building retrofit problem.

\section{MODELING FRAMEWORK}

The ZEO Uptake Analysis Tool represents an application of ABMS in the development of a learning tool, an estimation tool, and a scenario evaluation for technology uptake. This tool aims to discover and examine the interaction of various agents and their attributes on the uptake of commercial building retrofits, with the aim of forecasting future levels of uptake. Preliminary insights gained from the study results and scenario analyses will be useful in formulating future energy policy and intervention programs for building retrofits.

Information used in this case study is based on earlier work by Higgins et al. (2012) that forecasted technology adoption for the 15000 office buildings in NSW using system dynamic simulation. ABMS allows individual building retrofit behavior to be modeled in order to produce system-wide patterns from simple building interactions. This environment operates with three main components: buildings, retrofit options, and adoption criteria. In this case study, agents represent individual buildings (and their owners/managers) and are given characteristics and rules of behavior based on their building type. Agents select from a set of retrofit options based on a number of adoption criteria.

In order to study the patterns of technology adoption for the population of commercial office buildings in Victoria, we developed a typology to represent all possible categories of location by building type. The building typology defines a set of descriptive parameters that represent physical building characteristics, usage attributes, location information and other factors that affect the adoption of a broad range of technologies or policies. In order to keep the size of this initial typology small, the values of the different parameters have been limited to 2 or 3 categories whenever possible. The most important attributes of a building agent and their possible values are:

- $\quad$ Location (80 different LGAs)

- $\quad$ Building size (Low rise, Medium rise, High rise)

- $\quad$ Age (Pre 1980, Post 1980)

- Ownertype (Large owner, Medium owner, Small owner)

- $\quad$ Building grade (A/Premium, B, C, D)

\subsection{Uptake decision procedure}

For each building, the building owner (or manager) can decide to uptake or adopt any one of a number of retrofit options at any given time. Instead of identifying and detailing the myriad of individual retrofit options, we have decided to group these options into packages according to their purpose, cost and lifespan. Four retrofit packages were identified for the initial case study. The four option groups and the costs per square meter $\left(\mathrm{m}^{2}\right)$ they represent are described as follows:

1. Tuning Package - services tuning \& rebalancing (\$1.00), update of O\&M manuals (\$0.50), building users guide $(\$ 1.00)$

2. Chiller Package - chiller replacement $(\$ 34, \$ 68, \$ 63)$, boiler plant upgrade $(\$ 45, \$ 50, \$ 70)$

3. Beams Package - chilled beams $(\$ 400)$, Replace existing glazing with high performance glazing (\$180)

4. Solar Photovoltaic (PV) Package - PV (\$225.00 Low-Rise buildings only)@ \$1800/kW)

The decision to adopt an options package in a time period is based on a number of criteria. These criteria represent values, biases and preferences that the building owners attach to the options to calculate some measure of total attractiveness for the proposed package with or without any policy/incentive. Three criteria were identified from the available data. These are: 
1. Annual reduction in energy used in Megajoules (MJ) per $\mathrm{m}^{2}$ - depends on option package

2. Upgrade cost $(\$)$ of package per $\mathrm{m}^{2}$ - purchase price with or without incentive, which can depend on the building type;

3. Ability to retrofit (\%) - overall ability by a building owner to overcome a hierarchy of barriers, representing the socio-psychological factors affecting the decision.

The energy reduction and upgrade cost criteria represent the financial factors in the decision while the ability to retrofit represents the non-financial factors. Estimates of values for energy reduction and upgrade costs per option package and building type were obtained from Seo et al. (2015). The ability to retrofit for a building owner type is a percentage representing the probability of overcoming a cascading series of sociopsychological barriers to adopting retrofit packages. This probability is estimated from a series of tables containing evaluations as to whether specific barriers constitute a minor, moderate or major obstacle to retrofit adoption for a building owner type. The evaluations were obtained from surveys, expert advice and in consultation with Sustainability Victoria. Figure 1 shows a portion of the barrier probability evaluation process. Details of the barrier probability tables are presented in McGregor et al. (2015).

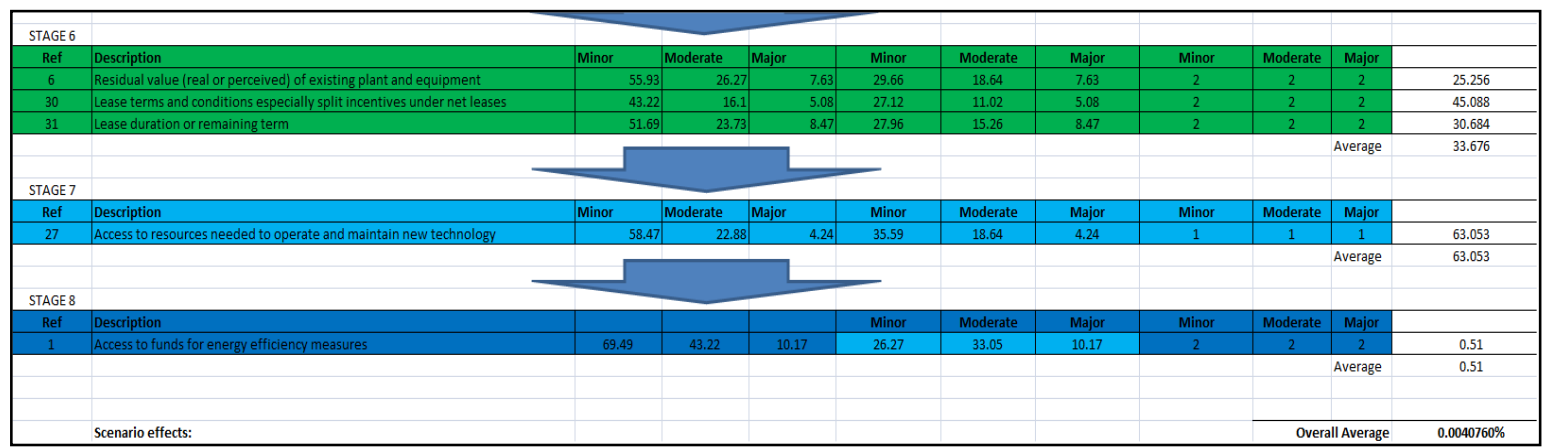

Figure 1. Evaluation of ability to retrofit using barrier probabilities.

Table 1 shows the three criteria with some of the parameters used. Columns $\boldsymbol{\beta}$ and $\boldsymbol{\alpha}$ in the criteria table represent the best and worst possible values for each criterion while the change factor indicates the annual change that occurs on the value of the criteria. The Age factor indicates that energy reduction values decrease as the retrofit options age while Inflation means that the upgrade cost increases over time due to inflation. These values are used to normalise the benefits of the option from each criterion. The probability of uptake of an option is then obtained by aggregating the weighted benefits extracted from each criterion as per equation 1 .

Table 1. Table of criteria for uptake with best $(\boldsymbol{\beta})$ and worst points $(\boldsymbol{\alpha})$.

\begin{tabular}{|l|l|l|l|l|}
\hline Criteria no & Name & $\boldsymbol{\beta}$ & $\boldsymbol{\alpha}$ & Change factor \\
\hline 1 & Energy reduction & 490 & 0 & Age \\
\hline 2 & Upgrade cost & 0 & 580 & Inflation \\
\hline 3 & Ability to retrofit & $100 \%$ & $0 \%$ & Fixed \\
\hline
\end{tabular}

The uptake of an option is defined as the adoption and operation of an option package under energy efficient conditions. Simply put, the uptake status of an option is TRUE if the option is being operated within its designated lifespan. Options that have exceeded their lifespan will have to be "re-adopted" (serviced and updated to energy efficient levels and their lifespan renewed) in order to maintain their uptake status. In order to adequately account for all benefits contributed by different types of criteria (economic, social, personal, etc), the building agent's decision module incorporates features of multi-criteria analysis and diffusion modelling. This provides a capability to calculate the probability of adopting (competing) technology options (e.g. different tuning, lighting, or chiller options) under any combination of criteria that a buyer would consider for a purchase.

This probability is computed as follows. Let the indices for the input parameters be defined as:

- $d \epsilon D$ is the index for the population of building agents.

- $o \in O$ is the index for the set of technology options (tuning, lighting, T65-BMS,..)

- $j \in J$ is the index for the set of criteria relevant to the technology option.

- $t \in T$ is the index for the time periods (0...80). Each time period represents three months and the simulation consists of 80 time periods. 
Let $x_{\text {otdj }}$ be the value of criterion $j \epsilon J$ for option package $o \epsilon O$ at time period $t \epsilon T$ for building agent $d \epsilon D$. Then the normalised criterion value $\boldsymbol{y}_{\text {otdj }}$ is given by

$$
\boldsymbol{y}_{\text {otdj }}=\left(\boldsymbol{\beta}_{\text {otdj }}-\boldsymbol{x}_{\text {otdj }}\right) /\left(\boldsymbol{\beta}_{\text {otdj }}-\boldsymbol{\alpha}_{\text {otdj }}\right)
$$

where $\boldsymbol{\beta}_{\text {otdj }}, \boldsymbol{\alpha}_{\text {otdj }}$ are the best and worst values, respectively, for criterion $j \epsilon J$.

Note that $\boldsymbol{y}_{\text {otdj }}$ represents the normalised distance (between 0 and 1) of the value $\boldsymbol{x}_{\text {otdj }}$ from the best point.

The aggregated benefits $\boldsymbol{\theta}_{\text {otd }}$ for option package $o \epsilon O$ at time period $t \epsilon T$ for building agent $d \epsilon D$ will now be given by the weighted sum of the normalised criterion values

$$
\theta_{\text {otd }}=\Sigma_{j \epsilon J}\left(w_{j} * y_{o t d j}\right)
$$

where $\boldsymbol{w}_{j}=$ weight of criterion $j \epsilon J$ and $\boldsymbol{\theta}_{\text {otd }}$ represents the total utility of adopting option package $o \epsilon O$ at time period $t \epsilon T$ for building agent $d \epsilon D$.

The probability of uptake of option package $o \epsilon O$ at time period $t \epsilon T$ for building agent $d \epsilon D$ will now be given by

$$
S_{d}(t)=\varphi\left(1-\quad \Delta * \exp \left(-\theta_{\text {otd }}\right)\right)
$$

where $\varphi=0.20$, a scaling coefficient, and $\boldsymbol{\Delta}$ is the weight given to each option utility value.

To evaluate this probability, generate a random value $\boldsymbol{v}_{\text {otd }}$ from a uniform $(0,1)$ distribution.

1. If $\boldsymbol{v}_{\text {otd }}<\boldsymbol{S}_{\boldsymbol{d}}(\boldsymbol{t})$, set uptake status $\boldsymbol{u}_{\text {otd }}=1$ (TRUE) and set the remaining life of option package $o \in O$ to a random value from a normal distribution with mean $=$ lifespan, and $\mathrm{sd}=0.1 *$ lifespan.

2. Otherwise, set uptake status $\boldsymbol{u}_{\text {otd }}=0$ (FALSE) and set the remaining life of option package $o \in O$ to 0 .

\subsection{Simulation procedure}

The simulation model is implemented in Anylogic 6.7 and run for 80 time periods where each year consists of four time periods. The steps performed in each simulation run are summarised as follows:

1. For each building type, generate an agent for each building under this type.

2. Assign the initial uptake levels of each option in each building type randomly among the agents.

3. For each iteration, determine the uptake status of each option for each building agent for the next time period. That is, for a given option in the current time period, if current uptake status is TRUE and the remaining life is greater than zero then next uptake status is TRUE and decrement remaining life by one time period. If current uptake status is FALSE or remaining life has reached zero then perform the uptake decision procedure.

4. Move to the next time period.

5. Update aggregated uptake counts for LGAs, building types, and options.

\section{DISCUSSION OF RESULTS}

A preliminary case study was conducted investigating the impact of three different EEOB policy scenarios on retrofit adoption by office building owners. The objective was to analyse the adoption patterns of a range of energy reduction opportunities from 2015 to 2035 across Victoria with and without the availability of support from the Government. The estimation procedure featured the application of agent-based modeling and simulation as implemented in the ZEO Uptake Analysis Tool. The Tool was calibrated and validated using observed EEOB adoption levels for 2013-2015.

For full details of the results of the case study, the reader is referred to McGregor et al. (2015).

\subsection{EEOB Scenarios}

Table 2 presents the attributes of three EEOB policy scenarios investigated in the case study. Scenario 1 investigates the extension of the existing EEOB program to provide building owners with subsidized energy audits up until the year 2035. In this scenario, EEOB contributes up to $50 \%$ of the implementation costs for building tuning activities identified in the audits up to a maximum contribution of $\$ 150,000$. Only mid-tier buildings ( $\mathrm{C}$ and $\mathrm{D}$-grade) are eligible for the program. Scenario 2 investigates an extension to the application of the existing EEOB program to 2035 along with expanding the technology options to chillers, beams and solar PV, in addition to tuning. Scenario 3 investigates the extension of the existing EEOB 
program to provide all building types with subsidized energy audits up to year 2035. In this scenario, EEOB contributes up to $50 \%$ of the implementation costs for building tuning activities identified in the audits up to a maximum contribution of $\$ 100,000$.

Table 2. Policy scenarios investigated in EEOB case study.

\begin{tabular}{|c|c|c|c|c|}
\hline Scenario & Name & Description & Cost Incentive & Eligibility \\
\hline $\begin{array}{l}1 \\
\text { (Original } \\
\text { Extended) }\end{array}$ & $\begin{array}{l}\text { EEOB } \\
\text { program }\end{array}$ & $\begin{array}{l}\text { An extension to the existing } \\
\text { energy efficient office building } \\
\text { program conducted from 2013- } \\
2015\end{array}$ & $\begin{array}{l}\text { Up to } \$ 150,000 \text { grant } \\
\text { (matching funds) } \\
\text { For tuning works only. }\end{array}$ & $\begin{array}{l}\text { Mid-tier building owners } \\
\text { only. (less than } 10,000 \\
\mathrm{~m}^{2} \text { and } \mathrm{C} \text { or } \mathrm{D} \text { Grade. } \\
\text { Around } 1009 \text { buildings.) }\end{array}$ \\
\hline $\begin{array}{l}2 \\
\text { (Four } \\
\text { Options) }\end{array}$ & $\begin{array}{l}\text { EEOB } \\
\text { Program } \\
\text { Mark } 2\end{array}$ & $\begin{array}{l}\text { An extension to the existing } \\
\text { energy efficient office building } \\
\text { program conducted from 2013- } \\
2015 \text { but expanding the } \\
\text { eligibility criteria to include all } \\
\text { technology options for upgrades } \\
\text { excluding lighting. }\end{array}$ & $\begin{array}{l}\text { Up to } \$ 100,000 \text { grant } \\
\text { (matching funds) } \\
\text { All technology options } \\
\text { (excluding lighting as it } \\
\text { is covers under VEET } \\
\text { scheme) }\end{array}$ & $\begin{array}{l}\text { Mid-tier building owners } \\
\text { only. (less than } 10,000 \\
\mathrm{~m}^{2} \text { and } \mathrm{C} \text { or } \mathrm{D} \text { Grade. } \\
\text { Around } 1009 \text { buildings.) }\end{array}$ \\
\hline $\begin{array}{l}3 \\
\text { (All building } \\
\text { types) }\end{array}$ & $\begin{array}{l}\text { EEOB } \\
\text { program - all } \\
\text { building } \\
\text { types. }\end{array}$ & $\begin{array}{l}\text { An extension to the existing } \\
\text { energy efficient office building } \\
\text { program conducted from 2013- } \\
2015 \text { but expanding the } \\
\text { eligibility criteria to include all } \\
\text { building types }\end{array}$ & $\begin{array}{l}\text { Up to } \$ 100,000 \text { grant } \\
\text { (matching funds) } \\
\text { For tuning works only }\end{array}$ & $\begin{array}{l}\text { All office building types. } \\
\text { (Around } 4200 \text { buildings.) }\end{array}$ \\
\hline
\end{tabular}

\subsection{Simulation Results}

For each of the three scenarios, three intervention conditions were considered. The conditions were:

1. No Incentive (denoted by "NI") - This condition represents the situation where there is no incentive for retrofit adoption from the government. Thus, all uptakes are made without using any incentive (Used Incentive $=$ No).

2. With Intervention at $100 \%$ Participation (denoted by "WI_100") - This condition represents the opposite extreme where the government incentive program (EEOB) is available with 100\% participation from owners. With $100 \%$ participation, all uptakes are made using the incentive (Used Incentive $=$ Yes).

3. With Intervention at $25 \%$ participation (denoted by "WI_25") - This condition represents the current situation where information on the EEOB Program has only reached $25 \%$ of the building owners. Thus, some uptakes are made using the incentive (Used Incentive $=$ Yes) while other uptakes are made without using the incentive (Used Incentive $=$ No).

Table 3 provides a summary of the key outputs for each scenario for the end of simulation period 80 (Year 20). The table shows the impact of the EEOB program over the NI (No Incentive) option at the $100 \%$ participation level (WI_100) and at the 25\% participation level (WI_25). Since there was no uptake for PV during the simulation period under Scenario 2, PV does not appear in the table.

For Scenario 1, the EEOB program applied to $\mathrm{C}$ and $\mathrm{D}$ grade buildings only would have just 15 more tuning uptakes (or $1.5 \%$ of the building population) over NI after 20 years. The cumulative energy savings from EEOB is around 82.9 million MJ more over NI at a cost of $\$ 2.75$ million, resulting in a return of around 8.39 $\mathrm{KwH}$ saved per $\$ 1$ invested by the government. However, if all buildings are covered (Scenario 3), the increase in uptake would be 45 bringing 511 million MJ more in energy savings at a cost of around $\$ 12.6$ million, and the KwH return would be 11.2. The biggest impact in energy savings is obtained from Chillers in Scenario 2 with 81 more uptakes over NI, saving 1230 million MJ more than NI at a cost of $\$ 33.21 \mathrm{M}$. For beams, there is no significant difference between NI and WI_100 near the end of the simulation, which means that the program brings no expected increase in the uptake of beams. 
Marquez et al., Modeling the adoption of energy efficient retrofits by mid-tier commercial buildings

Table 3. Comparison of key outputs for the three EEOB scenarios at the end of simulation period (Year 20).

\begin{tabular}{|l|l|l|l|r|r|r|r|}
\hline Scenario & Period & Option & Program & $\begin{array}{l}\text { Uptake } \\
\text { Impact over } \\
\text { No Incentive }\end{array}$ & $\begin{array}{l}\text { Energy Saving } \\
\text { (MJ) over No } \\
\text { Incentive }\end{array}$ & \multicolumn{1}{l|}{ Cost } & $\begin{array}{l}\text { Ratio (kWh } \\
\text { saved per \$1 } \\
\text { invested) }\end{array}$ \\
\hline 1 & 80 & Tuning & WI_100 & 15 & $82.9 \mathrm{M}$ & \$2.75 M & 8.39 \\
\hline 1 & 80 & Tuning & WI_25 & 1 & $88.7 \mathrm{M}$ & \$0.68 M & 36.23 \\
\hline 2 & 80 & Tuning & WI_100 & 2 & $131.0 \mathrm{M}$ & \$2.59 M & 14.06 \\
\hline 2 & 80 & Tuning & WI_25 & -8 & $24.4 \mathrm{M}$ & \$0.56 M & 12.10 \\
\hline 2 & 80 & Chiller & WI_100 & 81 & $1,230.1 \mathrm{M}$ & \$33.21 M & 10.29 \\
\hline 2 & 80 & Chiller & WI_25 & 40 & $308.4 \mathrm{M}$ & $\$ 9.80 \mathrm{M}$ & 8.74 \\
\hline 2 & 80 & Beams & WI_100 & -13 & $99.5 \mathrm{M}$ & \$4.00 M & 6.91 \\
\hline 2 & 80 & Beams & WI_25 & -8 & $-79.9 \mathrm{M}$ & $\$ 0.70 \mathrm{M}$ & -31.72 \\
\hline 3 & 80 & Tuning & WI_100 & 45 & $510.9 \mathrm{M}$ & \$12.64 M & 11.23 \\
\hline 3 & 80 & Tuning & WI_25 & 7 & $323.8 \mathrm{M}$ & $\$ 2.70 \mathrm{M}$ & 33.31 \\
\hline
\end{tabular}

\section{CONCLUSION}

In this paper we presented a framework that uses ABMS to study and understand the effects of rational and nonrational criteria in the adoption of energy efficient technologies for commercial building retrofits. The framework was applied in an exploratory case study which focused on the role of government programs such as the EEOB in the uptake of four retrofit packages for mid-tier commercial buildings in Victoria.

The analysis indicates that the proposed policy options offered by EEOB have very little impact when we consider small building owners and limit the application to building tuning only. There is improvement in uptake when we expand the eligibility to all technologies (excluding lighting) and this is dominated by HVAC (Chiller) upgrades. There is virtually no uptake of PV under the EEOB program over the simulation period. The table shows that the largest uptake and energy saving scenario relates to HVAC upgrades in Scenario 2 when we assume all building owners are aware of the policy. These scenarios also have very large program costs.

The best value for money option for the proposed policy scenarios relates to Scenario 3 where we expand the eligibility to upgrade tuning works to include all building types. Here we see a shift in uptake that is dominated by large building owners concentrated around the Melbourne CBD areas.

\section{REFERENCES}

Davis Langdon (2013) The Next Wave - Retrofitting Victoria’s Office Buildings, Summary Report, Prepared for Sustainability Victoria by Davis Langdon Australia Pty Ltd, http://www.sustainability.vic.gov.au/ /media/resources/documents/publications\%20and\%20research/publicat ions $/ \mathrm{m} \% 20-\% 20$ p/publications $\% 20$ the $\% 20$ next $\% 20$ wave $\% 20$ summary\%20report\%202013.pdf, Accessed July 2015.

Higgins, A., Syme, M., McGregor, J., Marquez , L., and Seo, S. (2012) Forecasting Uptake of Retrofit Packages in Office Building Stock: A Diffusion Modeling Approach, Low Carbon Living CRC, CSIRO.

Marquez, L., McGregor, J. and Syme, M. (2012) Barriers to the adoption of energy efficiency measures for existing commercial buildings. CSIRO Energy Transformed Flagship.

McGregor, J., Marquez, L., Seo, S., Walton, A., Moglia, M., Gardner, J., and Higgins, A. (2015) RP3002 - A Framework for Low Carbon Living Policy and Program Development - Sustainability Victoria Policy Scenario Case Study, Report RP3002 to the Low Carbon Living CRC, May 2015.

Seo, S. (2015) Energy saving potential from retrofit packages in commercial office building stock: A case of NSW, Australia, unpublished paper.

Sustainability Australia (2013) Energy Efficient Office Buildings Program: Guidelines and Application Form, Sustanability Victoria, September 2013, www.sustainability.vic.gov.au 